Check for updates

\section{Brussels}

Cite this as: BMJ 2021;372:n838 http://dx.doi.org/10.1136/bmj.n838 Published: 26 March 2021

\title{
Covid-19 vaccines: Europe tightens export criteria in bid to secure more doses
}

Rory Watson

Tighter European Commission criteria on exports of covid-19 vaccines from the 27 member bloc came into force on Friday 26 March, despite strong opposition.

The new rules introduce the two hurdles of reciprocity and proportionality. Exports to a country could be blocked if it restricts its own exports, either by law or contractual arrangements, or if its vaccine rates and supplies are better than the European Union's. The commission has repeatedly denied that it is planning an export ban targeting the UK. It does acknowledge, however, that "the mechanism gives us a certain leverage in negotiations with global vaccine producers."

The move aims to increase supplies of the four approved vaccines for the EU and tackle the slow rollout. It reflects increasing frustration in Brussels at the failure of manufacturers, particularly AstraZeneca, to deliver the amounts set out in advanced purchase agreements and at the millions of doses going to the UK, with few, if any, going in the other direction.

Supporters such as France, Italy, and Spain have welcomed the plan. But critics, notably Germany, Sweden, Belgium, the Netherlands, and the drug industry, have warned of disruptions to supply chains and a damaging "vaccine war."

The divisions emerged at a virtual summit in Brussels on the evening of 25 March. EU leaders did not openly endorse the commission's plan. Instead, a brief statement emphasised the need to accelerate "the production, delivery, and deployment of vaccines" and recognised the importance of global supply chains.

Supporters of the commission, however, will draw encouragement from the statement's agreement on "the use of export authorisations" and the need for companies to "ensure predictability of their vaccine production and respect contractual delivery deadlines." The arguments will continue next week when senior national officials examine in detail for the first time the implications of the new criteria.

Ursula von der Leyen, president of the European Commission, has justified the restrictions, saying, "The EU is the only major [Organisation for Economic Cooperation and Development] producer that continues to export vaccines at large scale to dozens of countries. But open roads should run in both directions." She told the summit that the EU had exported 77 million doses of vaccine since December, of which the UK had received 21 million. The commission also pointed out that AstraZeneca might deliver to the EU only 30 million of the contracted 120 million doses this quarter.
Previously, governments and the commission could refuse authorisation if the exports would prevent the manufacturer meeting its contractual commitments to the EU or threaten security of supply. That power has been used once in early March-to block a shipment to Australia-while 380 export requests for some 43 million doses to over 30 countries have been granted.

Since it announced the measures, AstraZeneca has requested EU approval for its Dutch vaccine plant, where it has produced millions of doses of vaccine but is unable to release them without approval from the European Medicines Agency. The UK has promised to work with the commission on a "win-win situation.”

Blocking exports will not necessarily increase vaccines for people in the EU. The commission has admitted that it cannot tell a company how to use any doses refused export authorisation as the company itself decides on their use. 